\title{
Desmantelando o monstro: o necrófilo de Gabrielle Wittkop
}

Anne Louise Dias

$\mathrm{UnB}$

\section{Resumo}

Gabrielle Wittkop fez da sua literatura um instrumento de transgressão de tabus, reconhecendo, ao longo de sua obra, a angustiante admiração humana pelos monstros cotidianos (Foucault). O presente estudo tem como objetivo principal abordar seu primeiro romance, Le nécrophile (O necrófilo), publicado em 1972, através da análise do comportamento desviante da personagem principal, o necrófilo Lucien. Procuramos aqui, principalmente sob as perspectivas da psicanálise, desvelar o entrelaçamento dos conceitos de desvio, perversão e violência quando no embate de uma prática necrofílica descrita como fruto do sentimento amoroso e que, com isso, rejeita e refuta as preconcepções de como enxergamos e entendemos o monstruoso.

Palavras-chave: violência; necrofilia; monstro; Outro; Gabrielle Wittkop.

\begin{abstract}
Gabrielle Wittkop turned her literature into an instrument of taboo transgression, recognizing, throughout her work, the anguishing human admiration for everyday monsters (Foucault). The main objective of this paper is to address her first novel, Le nécrophile (The necrophiliac), published in 1972 , through the analysis of the deviant behavior of its main character, the necrophiliac Lucien. We seek here, especially from the perspectives of psychoanalysis, to reveal the intertwining of the concepts of deviance, perversion and violence inserted in a necrophiliac practice described as the fruit of an amorous relationship and that, therefore, rejects and refutes the preconceptions of how we view and understand the monstrous.
\end{abstract}

Keywords: violence; necrophilia; monster; Other; Gabrielle Wittkop. 
Se o que o movimento renascentista propôs foi dar ao homem a posição central em todo tipo de produção intelectual, o século XIX elevou o indivíduo ao primeiro plano. A mudança do entendimento das formas das relações sociais trazidas com a revolução burguesa transformou por completo o tratamento dado à sociedade pela literatura. Em outro plano, ainda que não tão distante assim, a evolução histórica trouxe rupturas também no que hoje compreendemos e designamos como monstro. É, sobretudo, a partir da literatura do Marquês de Sade, no final do século XVIII, que eclode a figura do celerado, da criminalidade monstruosa, do monstro moral, que vai destronar o monstro teratológico. E Gabrielle Wittkop está embebida desse contexto.

Nascida Gabrielle Ménardeau, na cidade de Nantes, na França, casa-se ao final da guerra com um desertor alemão homossexual, Justus Wittkop, e instala-se em Frankfurt, onde viveu até seu suicídio, aos 82 anos, em 2002. Historiadora e ensaísta, Wittkop fez da sua literatura um instrumento de transgressão de tabus e um retrato de sua distinta relação com a morte. Em 1972 escreveu seu primeiro romance, o sulfuroso Le nécrophile, publicado por Régine Desforges, no qual retrata a história de Lucien, um necrófilo em atividade. $\mathrm{O}$ curto romance, escrito sob a forma de diário íntimo, parecia ter surgido em quase total indiferença, mas as poucas críticas dirigidas à obra reconheciam o elegante objeto literário acabado de surgir. Em 2001, a autora ganhou público renovado quando o leitor e amigo Nikola Delescluse, unido ao editor Bernard Wallet, reeditou "La Mort de C., seguido do Puritain passionné" e publicou seu novo livro, "Sérénissime assassinat", conto de estranheza e crueldade, ambientado na Itália do século XVIII.

$\mathrm{O}$ próprio estilo de Wittkop, muitas vezes associado àquele do Marquês de Sade, de Lautréamont e de Edgar A. Poe, tecido por uma linguagem simples, mas de intrincada delicadeza, abre-nos o caminho para o estudo de Lucien, protagonista de Le nécrophile, enquanto personagem desviante, por vezes perverso e violento, e igualmente decoroso amante - muito como a pena de Wittkop.

Nesse âmbito, o presente trabalho tem o objetivo de analisar o comportamento desviante do protagonista à luz de perspectivas advindas da sociologia da criminalidade, da filosofia e, sobretudo, da psicanálise para tratar as concepções de desvio, perversão e amor dentro do texto, elementos aliados ao embate entre o Eu e o Outro. A violência desse personagem literário é parte essencial para nós não apenas na análise da obra de Wittkop, mas também no que tange sua construção como produto e consequência de uma sociedade ocidental, que parece cada vez mais imersa no jogo brutal das relações afetivas; a literatura prostrando-se, então, como espelho das aflições da contemporaneidade. 
Para atingirmos nossos objetivos, essa pesquisa se desenvolverá a partir da análise do personagem de Lucien, partindo do papel identitário dos monstros em nossa cultura ocidental para desembocarmos nas implicações da prática da necrofilia como absolução e como fusão das figuras de Eros e Tânatos, aqui estreitamente entrelaçadas.

\section{Anormalidade e Necrofilia}

Foucault, em seu curso dado em 1974-1975 no Collège de France, aborda, a partir de fontes teológicas, jurídicas e médicas, o problema do indivíduo considerado perigoso, nomeado no século XIX de “anormal”. A nomenclatura não é, portanto, acidental: o anormal é aquele que foge à norma. Em realidade, algo só é considerado desviante quando comparado ao ordinário, e o papel da audiência é significante na criação do comportamento desviado, sujeito à sanção social.

O olhar do outro me constrói e contextualiza-me em tempo e espaço. A alteridade não apenas implica o reconhecimento e a discriminação das categorias do Eu e do Outro, como também rompe com a ilusão do Mesmo - tanto em nível individual quanto coletivo - e traz à superfície "o último ponto de referência do Outro" ": o monstro. A figura monstruosa surge como aquilo que é preciso negar, e sua representação, que une o impossível ao proibido, permite convencer o homem de que o real humano é racional. O conceito de alteridade, portanto, não se desvincula do de identidade, pois é com a percepção do desvio, do anômalo, que o homem pode pensar sua própria humanidade e normalidade.

Assim, Lucien pode ser considerado como um anormal, um monstro cotidiano (Foucault), porque nos faz atentar para a existência de sujeitos como ele, faz-nos reconhecer que todo indivíduo corre o risco de ser ou de se tornar monstruoso. Diante da presença do monstro, reconheço e asseguro minha normalidade. Nisso reside a angustiante atração do homem pelas figuras deformadas e amorais; a constatação da inquietante possibilidade de metamorfose, de devir-outro. A conduta de Lucien, seu amor pela decomposição física, faz dele um personagem limiar, transeunte assíduo de uma ponte entre vida e morte; mais ainda, o personagem elimina a distância entre as instâncias, pois não há qualquer estranhamento entre o vivo e o morto.

Muito se esquece de que o apontado como anormal não suscita apenas indagações em torno de seu comportamento moral, mas suscita também uma série de questionamentos 
ligados ao campo relacional e cultural. Em algumas culturas antigas, a necrofilia era praticada como meio de comunicação com os mortos ao mesmo tempo em que outros a enxergavam como uma tentativa de fazer renascer entes recém-partidos. Geralmente citada como condição rara, pouco se sabe precisamente sobre a prática. O termo necrofilia, aliás, que une os éti-

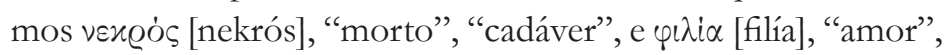
logo, amor pelos mortos ou cadáveres, parece ter surgido pela primeira vez com o alienista e reformador clínico belga, Joseph Guislain (1797-1860) em Lecons orales sur les Phrénopathies, escrito no inverno de 1850. No século XX, Rosman e Resnick (1989) analisaram 122 casos de necrofilia ao redor do mundo procurando entender, através de aspectos físicos, biológicos e psíquicos, a atração e a excitação sexual por cadáveres.

As definições variam entre os diversos autores, mas é possível distinguir, de forma geral, três tipos de necrofilia: a necrofilia dita verdadeira, na qual são mantidas relações sexuais com mortos; a necrofilia homicida, em que há assassinato com objetivos sexuais premeditados; e a necrofilia fantasiada, que diz respeito a fantasias sobre atos sexuais com mortos sem a realização destas. O estudo de Rosman e Resnick foi importante porque evidenciou que psicose, deficiência mental e sadismo não são características inerentes à prática necrofílica, além de identificar mecanismos de defesa associados aos necrófilos: negação da perda, introjeção de uma figura parental, reação contrafóbica do medo de mortos e a (auto)transformação de passivo para ativo. Sempre diagnosticados com profunda baixa autoestima, os necrófilos procuram trabalhar em funções que possibilitem o fácil acesso aos corpos, e o motivo mais comum da prática é a possessão de um parceiro que não resista e não rejeite os seus avanços.

Antes entendida como evidência de influências satânicas, a necrofilia nunca deixou de ser um tema produtivo. Wittkop cita a passagem do historiador e geógrafo grego Hérodoto, na qual ele menciona as precauções tomadas a fim de evitar o abuso de embalsamadores contra as belas mortas. Figuras históricas ilustres são associadas à prática, como Herodes, o Grande, Carlos Magno e o Rei Valdemar IV da Dinamarca. A necrofilia, em sua definição geral enquanto amor pelos mortos, estimulou o impulso criativo de vários escritores ao longo dos tempos, como Shakespeare (1599-1601) ou Cyril Tourneur (1608) até o Renascimento; teve seu fôlego renovado no século XIX, nos textos de Edgar Allan Poe, Théophile Gautier e Emily Dickinson; e desembocou no século XX através de Georges Bataille, William Faulkner, De Wargny, Cormac McCarthy, Bortnick, Davis e, finalmente, Wittkop. Mas, se o tema necrofilia é fio mediador que trespassa os autores supracitados, nenhum de seus personagens foi pincelado da mesma maneira. Todo monstro é original em 

inspecionado.

\section{O necrófilo de Wittkop}

O que se conhece do personagem principal da narrativa de Wittkop surge como uma trilha de migalhas a serem reagrupadas: seu aspecto físico e sua personalidade são desvelados pouco a pouco no decorrer de Le nécrophile. O lucífugo carrega em seu próprio nome a contradição de sua existência, Lucien, ser de luz, é representado como um Lúcifer não rejeitado pelos Céus, mas um que escolben e procura o recanto mais fundo do Inferno. Herdeiro da loja de antiguidades de seu pai, de sua aparência retemos apenas duas pequenas informações: a constatação da força de seus músculos superiores e a posição de seu membro por dentro das calças. Lucien descreve-se como nervoso, vulnerável, tímido e emotivo, ainda que assuma uma aura de tranquilidade, calma e prudência quando em contato com mortos. Obcecado por limpeza, um dos motivos pelos quais aprecia a condição dos cadáveres, "Ils ont déjà rejeté leurs excréments en quittant la vie"2, ele admite que é possível que não se incomode com o odor dos mortos por já ter se acostumado a viver envolto por ele.

Enclausurado, primeiro, pela clandestinidade de suas ações, Lucien refere-se com frequência a seu estado constante de tristeza e a suas vestes negras, companheiras apropriadas em seus passeios a cemitérios e para o comparecimento aos funerais de futuros amantes. Estes, contabilizados, formam a soma de doze relatos amorosos concretizados, entre homens (cinco) e mulheres (sete), entre elas uma anã corcunda e nas mais variadas idades: idosos, adultos, jovens, crianças e um bebê.

O que vamos coletando sobre Lucien reside também nas relações, embora fugazes, que ele mantém com os vivos: entre as empregadas desconfiadas de seu comportamento, do rapaz que tenta seduzi-lo e pelos encontros com outros necrófilos no decorrer da obra. Os significantes confrontos com a Morte desenham-na, aliás, como um Destino inexorável.

\section{Rastros da violência}

Diversos campos da sociologia já tentaram identificar um conjunto de razões para os desvios, desde motivos individuais, 
como biológicos e psicológicos, incluindo o desenvolvimento cognitivo e a interatividade social, até forças geográficas, culturais e estruturais. Por exemplo, sociobiólogos postularam uma teoria que considera a química do cérebro humano como determinante para o caminho desviante, enquanto sociobiólogos evolucionistas acreditam na existência de genes que controlam o padrão do comportamento humano. Em Le nécrophile, Gabrielle Wittkop não hesita em nos fornecer uma explicação psicanalítica para a conduta de Lucien. Nos hábitos masturbatórios, ainda quando criança - prática, aliás, à qual os médicos do século XVIII vinculam todo o arsenal de doenças corporais e mentais -, jaz o primeiro contato entre morte e prazer do personagem, pois é no odor exalado por sua mãe recém-falecida que o pequeno Lucien se vê assaltado pelo desejo necrofílico. O prazer pelo não-vivo atinge sem dúvida o campo da moral e são inúmeras as discussões sobre esse pretendido "crime sem vítimas". Entretanto, a trajetória ficcional, cuja duração é de três anos, relata-nos que Lucien se conduz para a experimentação de uma realidade bem mais tangível: a violência corpórea.

Os conceitos de pulsão de vida e de morte introduzidos por Freud forneceram importantes subsídios para o entendimento da violência, nem por isso ficaram isentos de possíveis ambiguidades. Freud reconhece na vida psíquica do ser humano a existência de um instinto de desintegração (do organismo) que persegue a meta de conduzir à morte o ser vivo e manifesta-se como tendência de destruição e/ou agressão. A postulação dessas ideias encaminhou-nos à compreensão da violência primeiramente como a satisfação dos impulsos e desejos destrutivos. Em uma segunda instância, porém, a violência também se vincula às questões de justiça e é posta a serviço da preservação da comunidade e da vida cultural, como diferenciou Derrida na dicotomia de law making violence (violência fundadora) e law preserving violence (violência conservadora). De fato, todas as sociedades humanas sustentam modalidades de agressividade que foram consagradas por lei ou banidas e depreciadas de acordo com os hábitos sociais prevalentes.

Faz-se frequentemente a distinção entre violência e agressividade - agressividade como instinto natural e violência como emprego desejado de tal impulso - e é igualmente comum o entendimento de uma equivalência entre violência, irracionalidade e descontrole emocional. Embora não haja indicação de que Lucien se sinta moralmente incomodado por seus desejos, dentre os diversos adjetivos com os quais podemos descrevê-lo, a adjetivação de irracional e descontrolado parece ser pouco adequada. É verdade que o fetichismo é raramente visto pelos fetichistas como um problema, mas Lucien é constantemente confrontado com eventos violentos, e seu desgosto pelo 
homem do cemitério que desventra uma jovem atriz morta, seu descontentamento pela comparação imprecisa entre necrofilia e vampirismo e seu ódio pela figura de Gilles de Rais ${ }^{3}$ comprovam o quão a brutalidade também o incomoda. Lucien revela-se meticuloso e inteligente no exercício de sua prática:

J'opère toujours avec une très grande rapidité et il ne me faut pas jamais plus d'une heure pour ouvrir la fosse, y descendre, soulever le courvercle du cercueil au ciseau à froid et, chargé du mort, remonter grâce à une technique soigneusement mise au point. ${ }^{4}$

Não obstante, a problemática da violência da necrofilia encontra-se em outras esferas. Impossível não evocar questões legais e, consequentemente, de poder. O criminoso é, por definição, aquele que prefere seu próprio interesse em detrimento das leis que regem a sociedade à qual pertence. E o crime é, portanto, "essencialmente da ordem do abuso de poder", ${ }^{5}$ no qual o transgressor substitui a lei pela lei de seu desejo. A relação entre desejo, lei e prazer é particularmente estreita no caso dos perversos. Muitos necrófilos veem na prática da necrofilia a possibilidade de se colocarem como agentes da situação, ao se sentirem em total controle de seus parceiros sexuais. O medo de policiais, citado algumas vezes pelo personagem Lucien, comprova sua consciência em relação às regras sociais. Ele compreende que apenas se arremete contra pessoas incapazes de se defenderem e chega, ele mesmo, a chamá-las de vítimas:

Quelqu'un d'encore plus bête que moi eût peut-être évoqué Gilles de Rais, non pas tellement en raison de l'enfant, qu'à cause de la position choisie, favorable à l'épanchement sur le ventre de celui qui d'ailleurs n'était pas ma victime. ${ }^{6}$

Em uma das entradas de seu diário, o protagonista relata sua impotência frente a Gabrielle, uma vizinha dos tempos de adolescência, e como imaginava miríades de maneiras segundo as quais a morte poderia alcançá-la, afim de, finalmente, poder tocar seu corpo. A conduta perversa de Lucien não visa senão à dominação, ao assujeitamento. Diante dos mortos, Lucien é superpoderoso. É esse jugo em relação ao outro que, assim como em Sade, transforma a simples libertinagem, o desejo desviante, em monstruosidade.

Quando invocamos o jogo de poder nas relações de Lucien, somos logo confrontados com a questão da violência sexual. Sabemos que o estupro é um ato de controle e violência que usa os órgãos sexuais, e não apenas um ato sexual particularmente agressivo. Contudo, na legislação brasileira, a necrofilia configura vilipêndio de cadáver e não estupro. Isso porque duas
3. Gilles de Montmorency-Laval, Gilles de Rais, ou Gilles de Retz (1404-1440), barão de Rais e nome imponente do exército francês, lutou ao lado de Joana D’Arc. Foi acusado de estupro, tortura, mutilação e assassínio de mais de 150 crianças (alguns estudiosos chegam a estimar 800).

4. Ibidem, p. 26.

5. FOUCAULT, Michel.

Os anormais, 2001, p. 115.

6. WITTKOP, Gabrielle.

Le nécrophile, 2001, p. 66. 
7. David Archard, apud. GOODWINN, Robin. Inappropriate Relationships: the unconventional, the disapproved and the forbidden, 2002, p. 183. perguntas fazem-se essenciais na discussão: seria possível causar dor e/ou sofrimento a um corpo morto? Seria apropriado avaliar o ato da necrofilia em termos de violação do princípio fundamental do consentimento sexual? Já mencionamos anteriormente que a possibilidade de um parceiro não-rejeitante é motivo principal para a prática necrofílica (Rosman e Resnick apontam essa como a razão principal de $68 \%$ dos casos analisados). Lucien também se engaja, ainda que sem consumação de fato, em relações sexuais com uma mulher viva e, mesmo ali, a noção de permissão, para ele, não parece ser um empecilho. Além disso, Lucien sempre banha os mortos em água quente e entende o enternecimento da carne fria como uma aquiescência; enxerga sensualidade na protelação. A rejeição, aliás, é fonte de aborrecimento e induz o fim do prazer. Archard', entretanto, defende que o interesse pessoal pode ser estendido muito além do corpo meramente biológico e, independentemente do efeito traumatizante indireto nos parentes da vítima ou mesmo da transgressão de tabus, a necrofilia seria moralmente errada e deve ser, sim, entendida como transgressão sexual.

\section{Amor como absolvição}

Se sexo, no sentido de contato físico, e morte estão intimamente ligados no personagem de Lucien, assim também se encontra o amor. $\mathrm{O}$ amor, como a necrofilia, é força equívoca, sexuada e transgressora de status social. Mas nem o amor, sentimento tão afamado, foge à dificuldade de conceituação. Os filósofos oscilam em pontos extremos. Platão afirma que, no amor, há o germe do universal. Schopenhauer amaldiçoa as mulheres que amam por darem continuidade à espécie humana. Kierkegaard, por outro lado, transforma o amor em pura experiência subjetiva, em meio de ascender ao supra-humano. Ele separa, ainda, o amor em três estados: o estado estético, de amor sedutor, egoísta; o estado ético, que corre em direção ao absoluto; e o estado religioso, sancionado pelo casamento. $\mathrm{Na}$ psicanálise, Lacan cerra a definição de amor com a de sexualidade. Ou melhor, divide-as afirmando que o sexual por si só não une, mas separa. Enquanto no sexo estamos em relação com nós mesmos pela mediação do outro, é somente no amor que o homem vai além do narcisístico. Isso porque a experiência afetiva é a experiência da diferença, da experimentação do ponto de vista do outro. $\mathrm{O}$ amor é a vivência da alteridade, pois impõe o confronto de duas representações diferentes. Seria, portanto, questionável classificar a necrofilia como um tipo de relacionamento. Voltamos sempre ao embate entre o eu de Lucien e o outro sujeitado. 
A importância do corpo faz-se mais uma vez presente. Apenas apreendemos a subjetividade do outro através de uma experiência indireta: a percepção das emoções e dos pensamentos só pode ser feita por mediação do corpo físico, de suas indicações corporais. Lucien, amante de cadáveres, mais do que ninguém, necessita da esquematização do interior pelo exterior. No espaço exterior, pode-se ver emergir a alma. Não é por acaso que o protagonista lamenta a evisceração de uma pretendida amante, pois é negado ao cadáver eventrado, mutilado, o lugar de sua alma. Na descoberta do corpo de seus parceiros - da concierge que o presenteia com seus seios jovens; de Henri, o menino morto de escarlatina, que permite o acesso a sua entrada; da virgem de Ivry, que suga sua semente; em suas reações -, Lucien forma o vínculo íntimo com eles e os contempla "[je les contemplais] longuement, reconnaissant de ce spectacle comme d'une grâce" ". É importante ainda ressaltar que amor e necrofilia não estão intrinsecamente ligados apenas no protagonista de Wittkop nem se configuram uma ferramenta literária. Jones (1931) e, recentemente, Aggrawal (2008) assinalaram, além da classificação tríade supracitada, outro tipo de necrofilia que constata a prática necrofílica entre pessoas que não suportam a perda de seus parceiros. Nesses casos, é comum a mumificação de entes queridos para a continuidade do contato sexual. O necrófilo acende a vida na morte. Faz as pazes com ela.

Mas, não há dois amantes na relação; o necrófilo ama sozinho. E é no vazio da relação sexual, em si mesma problemática, que Lucien está fadado à eterna repetição. Sinal irrecusável do conflito psíquico, a repetição é uma transferência do passado esquecido. Em Lucien, configura-se uma repetição diferencial, uma vez que fonte de transformações. Desse retorno às fantasias, às emoções passadas, ele se encarrega de uma missão. Pois, embora esteja clara a influência do complexo de Édipo na construção da perversão do protagonista da narrativa, não é a busca da figura materna o centro das relações de Lucien. Na verdade, amar os corpos após o óbito é uma forma de lhes oferecer tudo o que a morte os privou: da contemplação do corpo virgem, da atenção amorosa, do contato da pele. Com os gêmeos, o protagonista proporciona a união na morte. Ele lhes fornece a vida eterna e, em seu amor, parece aceder à "vérité cosmique", ao absoluto. Ao tempo que acolhe a eternidade. Incumbido de amá-los, Lucien sente-se perdoado e põe-se à altura da subjetividade. O necrófilo defende: "Amour nécrophilique, le seul qui soit pur"10.

A pureza desse amor altruísta une-se ao estilo escolhido na composição do romance. A necrofilia foi tema de diversas narrativas literárias, mas foi Gabrielle Wittkop que deu finalmente voz ativa ao amante dos mortos. A necrofilia requer a abolição total do olhar reprovador, da mediação do narrador, para
8. WITTKOP, Gabrielle. Le nécrophile, 2001, p. 91-92.

9. Ibidem, p. 91.

10. Ibidem, p. 49. 
poder enfim ser contemplada. Álvares de Azevedo com Solfieri, personagem de Noite na Taverna, também elimina o intermédio do narrador, é verdade, mas deixa bastante clara a ocorrência singular de tal encontro, impulsionado principalmente pelo vinho ingerido. Ainda assim, não passa despercebida em Noite na Taverna a ligação inconfundível entre desejo e morte: a vítima de Solfieri sofrera apenas um ataque de catalepsia, mas a consciência do que havia acabado de acontecer encaminhou-a primeiro para o delírio e, depois, enfim, à morte. Lucien, por sua vez, parece nos atingir de forma mais profunda. Ele nos choca na mesma medida que nos comove, porque rompe com a dualidade sistemática do bom e do mau. Ele toca o campo de nossas resistências - de todas as resistências que compõem o não-eu e faz-nos questionar a maneira pela qual o concebemos. Lucien alia o familiar às instâncias mais ocultas do ser. $\mathrm{O}$ amor necrofílico incomoda porque cria um personagem abominável com o qual podemos sentir empatia. Lucien é a representação assertiva de que amar os mortos é tão difícil quanto amar os vivos. É viver em pleno luto.

\section{O amálgama}

O irrefreável embate entre vida e morte não é recente. Sêneca já havia apontado como a natureza joga com os contrários e com a harmonia que deles deriva. Quando Freud reconheceu a presença do instinto de morte em nossa psique, também admitiu a existência de instintos de vida, reunidos sob o nome de Eros. Na verdade, os instintos de autopreservação exigem a mescla à agressividade para o seu funcionamento. E impulsos agressivos e cruéis se acham intimamente ligados ao prazer e à gratificação. Lucien é a prova de que a amalgamação entre morte e vida e, além, morte e amor, não pode ser destruída. $\mathrm{Na}$ mitologia, o ponto de fusão de dois em um leva à morte; Tristão e Isolda são arquétipos da ligação profunda entre morrer e amar. A angústia constante de Lucien serve igualmente como ponte entre vida, experiência amorosa e morte.

O necrófilo de Wittkop transita além do reino da vivência mundana e procura, na experiência do amor dos mortos, enxergar o não-ser, o não-sentido. Ele procura acordar o absurdo da existência humana. Lucien descende ao Hades no corpo de Suzanne - possivelmente sua primeira amante. Nela, ele vive a morte. E é ao transformar seu quarto em Templo da Morte que Lucien revela as incongruências de amar os mortos. O cadáver em si já é dual, pois nos aparece como sagrado e intocável, 
divino e maligno, solene e perturbador. Mas, o que seria um golpe contra o sagrado é, em Le nécrophile, a transformação do corpo em objeto de um culto particular, um culto que honra, mais do que profana. Apagam-se os limites entre a sujeição sexual e a sacralização do corpo violentado. A metáfora com Jesus, "On eût dit quelque "Christ au tombeau" dans les bras d'un profane Joseph d'Arimathie"11, feita pela própria Wittkop, faz-se, portanto, imprescindível. O Cristianismo seria então o exemplo supremo da utilização da intensidade amorosa dentro de uma concepção transcendente.

O depressivo é cativo do afeto. $\mathrm{Na}$ tristeza, ele se confunde com o Outro. Pode-se pensar que a perversão de Lucien seja uma defesa contra a depressão psicótica manejada em forma de tática de intimidade. No reconhecimento do corpo, Lucien precisa lidar com mais duas ideias contraditórias: o corpo é fonte de prazer, mas é também fonte de sofrimento. A multiplicidade das relações construídas no romance incide, sobretudo, em como o amor de Lucien é incapaz de viver a continuidade, porque ele mesmo é aniquilação. No personagem de Suzanne, com quem ele compartilha quatorze dias trancados no quarto gélido, sem comida, sem contato com o exterior, Lucien repreende-se por ter afastado "[j'éloignais de Suzanne] tout ce qui pouvait lui nuire. Sauf moi, hélas!"12. O necrófilo compreende que, se tivesse embalsamado Suzanne, ele poderia mantê-la junto a si pela eternidade. Entretanto, em sua cobiça de possuí-la, acaba permitindo a deterioração do corpo. Ele a cerca de sacos de gelo, porém logo percebe que seu egoísmo não permitiria a permanência de Suzanne em sua vida. Nunca mais. Esse jogo de oposições é tão singular que mesmo o odor do bomby $x^{13}$, gatilho importante para a excitação de Lucien, é também anúncio de separação irrefreável causada pela putrefação. Se a morte completa, ela amputa logo em seguida. Tudo tem em si o germe da própria destruição.

\section{Considerações Finais}

O presente trabalho procurou analisar o comportamento do protagonista do romance escrito por Gabrielle Wittkop, o necrófilo Lucien, evitando uma conceituação sistematizante de violência para compreendê-la em suas mais diversas manifestações, associada principalmente a uma conduta que escapa ao que se constitui como norma. Apresentamos aqui amor e violência de forma separada e em tópicos, por motivos meramente metodológicos, contudo, guiados pelo conceito de diferença, a
11. Ibidem, p. 59.

12. Ibidem, p. 40.

13. Designação comum aos insetos lepidópteros, que incluem as mariposas, do gênero Bombyx. Seu representante mais comum é o Bombyx mori, vulgarmente conhecido como bicho-da-seda. 
verdade que se coloca é a impossibilidade de separá-los. Existe fantasmagoria na existência de Lucien, porque, ao reconhecê-lo como outro, sou eu mesmo modificado em meu processo de autoidentificação. Não existe retorno depois de conhecer o monstro. Depois de abraçá-lo.

A violência que surge do amor é uma experiência de prazer perverso, ao mesmo tempo em que cria a ligação mais intensa de amor como alquimia sublime. O protegido de Hécate, deusa das encruzilhadas, habitante do submundo, reinventa o Inferno, agora não mais um lugar mítico para onde se encaminham as almas, e sim um corpo, um sepulcro onde deságua sua semente. Seu sexo. Seu coração.

Partilhar a trajetória de um personagem que não crê mais em sacrilégios, significa confrontar situações as quais muitas vezes preferiríamos ignorar. O desenterro do cadáver põe em questão nossa relação com o corpo gelado, inanimado, e principalmente com a Morte, verdade universal para todas as instâncias vivas. Um pouco como Humbert Humbert, o pedófilo padrasto de Lolita, de Nabokov, o Lucien de Wittkop, com seu humor negro e sutil, provoca-nos e questiona-nos: você consegue ver para além do perverso?

\section{Referências}

AGGRAWAL, Anil. "A new classification of necrophilia". Journal of Forensic and Legal Medicine, n. 16, p. 316-320, 2009. Disponível em: < http://www.anilaggrawal.com/ij/sundry/ news_and_notes $/ 316 \_$A $\% 20$ new $\% 20$ classification $\% 20$ of $\% 20$ necrophilia.pdf $>$. Acesso em: 30 abr. 2017.

. Necrophilia: Forensic and medical-legal aspects. New York: CRC Press, 2010.

ALMEIDA, Rogério Miranda. Eros e Tânatos: A vida, a morte, o desejo. São Paulo: Edições Loyola, 2007.

AULAGNIER-SPAIRANI, Piera et al. Le désir et la perversion. Paris: Éditions du seuil, 1967.

AZEVEDO, Álvares de. Noite na Taverna. São Paulo: L\&PM Editores, 1998.

BADIOU, Alain; TRUONG, Nicolas. Éloge de l'amour. Paris: Flammarion, "Champs essais", 2009. 
DERRIDA, Jacques. "Force of law: The Mystical Foundation of Authority". In: Deconstruction and the possibility of

justice. London: Routledge, Chapman \& Hall, Inc., 1992. L'écriture et la différence. Paris: Éditions du Seuil, 1967.

COSTA, Jurandir F. Violência e psicanálise. Rio de Janeiro:

Edições Graal, 2003.

FOUCAULT, Michel. Os anormais. Trad. Eduardo Brandão.

São Paulo: Martins Fontes, 2001.

FRAPPAT, Hélène (Org.). La violence. Paris: GF Flammarion, “Corpus", 2000.

FREUD, Sigmund. "História de uma neurose infantil ("O homem dos lobos")", Além do princípio do prazer e outros textos. In: Obras completas, v. 14. Trad. Paulo César de Souza.

Companhia das Letras. São Paulo: 2010.

- "Psicologia das massas e análise do Eu e outros

textos". In: . Obras completas, v. 15. Trad. Paulo César de

Souza. São Paulo: Companhia das Letras, 2010.

GARCIA-ROZA, Luiz Alfredo. Acaso e repetição em psicanálise: uma introdução à teoria das pulsões. São Paulo: Jorge Zahar, 2003.

GIL, José. Monstros. Lisboa: Relógio d'Água Editores, 2006. . Metamorfoses do corpo. Lisboa: Relógio d'Água editores, 1997.

GOODWIN, Robin; CRAMER, Duncan. Inappropriate Relationships: the unconventional, the disapproved and the forbidden. London: Routledge, 2002.

KLEIN, Melanie; RIVIERE, Joan. Amor, ódio e reparação: as emoções básicas do homem do ponto-de-vista psicanalítico. Trad. Maria Helena Senise. Rio de Janeiro: Imago editora, 1970.

KRISTEVA, Julia. Soleil noir. Dépression et mélancolie. Paris: Gallimard, "Folio essais ”, 1987.

LOBO, Sônia (Org.). Violência: um estudo psicanalítico e multidisciplinar. Fortaleza: Edições Demócrito Rocha, 2003.

PAJAZCKOWSKA, Claire. Conceitos de Psicanálise: Perversão. Trad. Carlos Mendes Rosa. São Paulo: Ediouro, 2005.

PONTALIS, Jean-Bertrand (Dir.). L'amour de la haine. Paris:

Gallimard, "Folio essais ”, 1986. 
ROSMAN, Jonathan P.; RESNICK, Phillip J. "Sexual Attraction to Corpses: A Psychiatric Review of Necrophilia". Journal of the American Academy of Psychiatry and the Law, n. 17, p. 153-163, 1989.

ROSSI, Henri. "La nécrophilie comme chaste pratique. Propos sur Le nécrophile de Gabrielle Wiitkop-Ménardeau”. In: CASTA, Isabelle. Le chaste et l'obscène. Paris: Editions Publibook, 2004.

SAVIGNEAU, Josyane. “Gabrielle Wittkop”. Le Monde, Paris, 25 déc. 2002.

. "Gabrielle Wittkop, sulfureuse et convenable". Le Monde, Paris, 19 janv. 2001.

WITTKOP, Gabrielle. La Marchande d'enfants. Paris: Éditions Verticales, 2003.

. Le nécrophile. Paris: Éditions Verticales, 2001. . Les Départs Exemplaires. Paris: Édition Verticales, 2001. . Sérénissime assassinat. Paris: Éditions Verticales, 2001. 